\title{
A study on cervical cancer awareness among the Bengalee women, Kolkata, West Bengal
}

\begin{abstract}
Background: Cervical cancer is a widespread and often fatal disease, it is not only the second most common cancer in women but it is the second leading cause of cancer death. The present study aims to understand the knowledge, attitude and practices regarding cervical cancer prevention among the females of Calcutta University.
\end{abstract}

Methods: A structured questionnaire with multiple choices was used for data collection. Data were analyzed in SPSS 16.0. A total of 100 participants were included in the present study.

Results: The study presents varying frequencies and interesting picture about the knowledge and awareness of a disease that needs attention. Majority of the respondents reported miscarriage, abortion and smoking to be leading causes of cervical cancer.

Conclusion: The study presents frequencies of knowledge and attributes about cervical cancer awareness. This study can be further utilized to frame awareness programmers to make females conscious of the preventive and prognosis of cervical cancer which would ultimately benefit the overall public health related to women.

Keywords: cervical cancer, awareness, Bengalee Hindu, females West Bengal
Volume 4 Issue 3 - 2017

\section{Abhishikta Ghosh Roy, ${ }^{1,2}$ Arpita Roy, ' Arup Ratan Bandyopadhyay'}

'Department of Anthropology, University of Calcutta, India 2DNA Laboratory, Anthropological Survey of India, India

Correspondence: Abhishikta Ghosh Roy, Department of Anthropology, University of Calcutta, 27, Jawaharlal Nehru Road, Kolkata , 700 016, India,Tel +91-983678/302, Email abhishikta.gr@gmail.com

Received: March 30, 2017 | Published: April 06, 2017

\section{Introduction}

Cervical cancer is considered to be a preventable health problem, but each year nearly about 530,000 women worldwide contract the disease. 275,000 women die from cervical cancer at the same time almost. ${ }^{1}$ This makes cervical cancer the second most common cancer and third in terms of cancer-caused deaths among women worldwide. ${ }^{2}$ Cervical cancer affects mostly women under 50years of age. ${ }^{3}$ Multiple social barriers for accessing basic screening and treatment services have posed or taking the Indian women at greater risk of developing the disease. ${ }^{4}$ Eighty-six percent of all cervical cancer diagnosed and $88 \%$ of death due to cervical cancer occur in developing regions of the world. Cervical cancer is the most frequent cancer among women between 15 and 44 years of age in India. ${ }^{5}$ India bears about one fifth of the world's burden of cervical cancer. More than 100,000 new cases are detected in India per year and it causes 20 percent of all female deaths in India. ${ }^{6}$

The mortality rates of cervix cancer are very high so early detection and treatment is the only solution to it. The primary underlying cause is human papillomavirus (HPV), which is the most common sexually transmitted infection worldwide with women having multiple sex partners or who have sex with men who had many other partners. Other causes of cervix cancer include smoking, low consumption of fruit/vegetable, family history. ${ }^{8}$ The human papillomaviruses (HPVs) are a large group of viruses, about 40 of which can infect the human genital tract. Some HPVs are known to cause cervical cancers, while others cause genital warts. Most genital HPV infections go away on their own, but when they become chronic, they can cause precancerous and cancerous changes in the cells that line the uterine cervix. Over $90 \%$ of cervical cancers are caused by HPV infection. HPV infection is extremely common. In fact, most men and women who have ever had sex will contract the infection at some point in life. In some people, the infection persists for years, even if they are not sexually active. Condoms may lower the risk of acquiring the infection, but they are not $100 \%$ effective. HPV is also known to cause cancers in other areas of the body, including the penis, anal area, vulva, vagina, and oral cavity.

Multiple sexual partners, early age of onset of sexual activity, increasing parity, use of hormonal contraceptives for 5years or longer, ${ }^{4}$ current or previous sexually-transmitted infection and smoking ${ }^{9}$ are the risk factors for cervical cancer. The most common symptoms and signs of cervical cancer are abnormal vaginal bleeding, increased vaginal discharge, bleeding after going through menopause, pain during sex, and pelvic pain. Vaccines are available to prevent infection with the types of HPV most likely to cause cancers. Cervarix and Gardasil are two vaccines that require three shots over a 6-month time period. Gardasil also protects against the two types of HPV that most commonly cause genital warts.

A study on awareness of Cervical Cancer was conducted by A Saha et al. ${ }^{12}$ to explore knowledge and awareness of the students of four elite women's colleges in Kolkata about cervical cancer the study analyzed a probable relationship between the overall knowledge level and a few socio demographic parameters in the exposure to the disease. A recent qualitative study (Bingham A, Drake JK, et al. 2009) reported a low level of knowledge on HPV and cervical cancer among children, parents, teachers, community leaders and even health service providers of four developing countries (India, Peru, Uganda and Vietnam). Very similar results, i.e. lack of proper knowledge regarding cervical cancer, were found in several studies conducted in other countries in the world. ${ }^{10} \mathrm{~A}$ study conducted on the awareness of cervix cancer risk factors among the youth of India, Nepal and Sri Lanka with respect to socio demographic factors by Teresa J. Among the three nationalities the proportion of youth who were aware of 
cervix cancer was found to be $65.9 \%$ (Indian), $58.6 \%$ (Nepal) and $57.7 \%$ (Srilankan). A number of studies trying to assess knowledge and attitudes towards cervical cancer have already been conducted but this study focused mainly on the knowledge about the risk factors associated with the disease. Studies have been done among the college students in Kolkata, but no such awareness work is been done in the Ballygung science college campus. Hence the study is been conducted among the educated women of Calcutta university to find out the knowledge of the disease among them. As recent studies in India show that public awareness of the subject of cervical cancer is insufficient. ${ }^{11}$ Thus the project focuses either the women are aware of the threatening disease which they may acquire at any time span of their life due to certain misconceptions or incorrect knowledge. Cervical cancer affects mostly women under 50years of age. ${ }^{3}$ Thus the participants up to under the age of 50years are chosen for the study.

\section{Objectives}

The aim of this study was to understand the level of general knowledge about cervical cancer, its risk factors, prevention, and symptoms.

\section{Materials and methods}

The sources of information are obtained with the help of a questionnaire designed for knowing the general awareness about the disease among the women (both married and unmarried) of Calcutta University. A structured questionnaire with multiple choices was used for data collection. Data entry was done in Microsoft Excel. Analysis table are made from the data and from it the results are obtained. The questionnaire focused on the problem of awareness about cervical cancer. The questionnaire has four broad sections.

The first part of the questionnaire includes some basic questions related to the primary knowledge about the disease. The second part deals with the major risks factors which may or may not be associated with the disease, the participants were asked to mark them in number range $0-5$, the risk factor which is strongly associated with the disease is asked to mark 5 and the risk factor with no association is to be marked as 0 , and as the number range increasing from 0 to like 1,2 , 3 , or 4 it is used to show increasing association of the risk factor with the disease. The third part includes the knowledge about prevention of the disease among the women and the last part deals with the sources of information of the participants regarding the disease. Sampling method- The sample is randomly chosen among the women of Calcutta University of 20-50 years age group.

\section{Number of participants}

The total number of participants in the study is 100 including both married and unmarried women.

\section{Area of study}

The study was conducted in the Calcutta University campus at Ballygunge Science College.

\section{Results}

Of all the study participants $34 \%$ were married and $64 \%$ participants were unmarried. From the study it is obtained that $86 \%$ of the people heard about cervical cancer, $12 \%$ haven't ever heard about it. While $2 \%$ knows very little about it. $62 \%$ believe that a women can die from cervical cancer, $6 \%$ thinks a women cannot die out of it.
Again 15\% people thinks may be a women can die, $5 \%$ are not sure about it. $8 \%$ people don't know about it. $2 \%$ people haven't heard and $2 \%$ people haven't answered the question. $49 \%$ participants think that cervical cancer is associated with an infection, $14 \%$ does not agree with an association of infection. According to $19 \%$ people it is may be associated with an infection. $9 \%$ people are not sure about it, $7 \%$ people don't know about it and 2\% people haven't answered. $4 \%$ of people's relative or friends are suffering from cervical cancer and $96 \%$ people claim they do not know any of the patients of cervical cancer.

The various risk factors are marked from (0-5) in increasing order of the relationship with the disease. It has been seen that $45 \%$ of people thinks young age has no relationship with the disease while $14 \%$ thinks it is weakly related, $6 \%$ thinks it is less weak, $17 \%$ people thinks it is medium, $9 \%$ thinks it is less strong, while $9 \%$ people haven't answered. It has been seen that $7 \%$ of people thinks genetic factor has no relationship with the disease while $9 \%$ thinks it is weakly related, $14 \% \%$ thinks it is less weak, $21 \%$ people thinks it is medium, $21 \%$ thinks it is less strong, $25 \%$ people thinks it is strongly related, While 3\% people haven't answered. It has been seen that $7 \%$ of people thinks HPV infection has no relationship with the disease while $3 \%$ thinks it is weakly related, $14 \%$ thinks it is less weak, $21 \%$ people thinks it is medium, $17 \%$ thinks it is less strong, $27 \%$ people thinks it is strongly related .while $11 \%$ people haven't answered. It has been seen that $4 \%$ of people thinks having multiple sexual partners has no relationship with the disease while $8 \%$ thinks it is weakly related, $6 \%$ thinks it is less weak, $12 \%$ people thinks it is medium, $26 \%$ thinks it is less strong, $40 \%$ people thinks it is strongly related, while $4 \%$ people haven't answered. It has been seen that $5 \%$ of people thinks HIV infection has no relationship with the disease while $40 \%$ thinks it is weakly related, $11 \%$ thinks it is less weak, $18 \%$ people thinks it is medium, $27 \%$ thinks it is less strong, $29 \%$ people thinks it is strongly related, while $6 \%$ people haven't answered. It has been seen that $29 \%$ of people thinks alcohol use has no relationship with the disease while $9 \%$ thinks it is weakly related, $13 \%$ thinks it is less weak, $23 \%$ people thinks it is medium, $11 \%$ thinks it is less strong, 3\% people thinks it is strongly related, while $12 \%$ people haven't answered.

It has been seen that $31 \%$ of people thinks smoking has no relationship with the disease while $8 \%$ thinks it is weakly related, $20 \%$ thinks it is less weak, $13 \%$ people thinks it is medium, $16 \%$ thinks it is less strong, $7 \%$ people thinks it is strongly related, while $5 \%$ people haven't answered. It has been seen that $36 \%$ of people thinks miscarriage and abortions has no relationship with the disease while $12 \%$ thinks it is weakly related, $16 \%$ thinks it is less weak, $12 \%$ people thinks it is medium, $10 \%$ thinks it is less strong, $6 \%$ people thinks it is strongly related, while $8 \%$ people haven't answered.

It has been seen that $37 \%$ of people thinks large number of pregnancy \& childbirth has no relationship with the disease while $11 \%$ thinks it is weakly related, $2 \%$ thinks it is less weak, $19 \%$ people thinks it is medium, $7 \%$ thinks it is less strong, $11 \%$ people thinks it is strongly related, while $5 \%$ people haven't answered. It has been seen that $41 \%$ of people thinks early menarche has no relationship with the disease while $16 \%$ thinks it is weakly related, $12 \%$ thinks it is less weak, $11 \%$ people thinks it is medium, $9 \%$ thinks it is less strong, $0 \%$ people thinks it is strongly related, while $11 \%$ people haven't answered. It has been seen that $28 \%$ of people thinks use of condom has no relationship with the disease while $8 \%$ thinks it is weakly related, $17 \%$ thinks it is less weak, $16 \%$ people thinks it is medium, $8 \%$ thinks it is less strong, $12 \%$ people thinks it is strongly 
related, while $11 \%$ people haven't answered. It has been seen that $6 \%$ of people thinks taking hormonal contraception has no relationship with the disease while 5\% thinks it is weakly related, $15 \%$ thinks it is less weak, $26 \%$ people thinks it is medium, $24 \%$ thinks it is less strong, $12 \%$ people thinks it is strongly related, while $12 \%$ people haven't answered.

It has been seen that $60 \%$ of people thinks breast feeding has no relationship with the disease while $14 \%$ thinks it is weakly related, $9 \%$ thinks it is less weak, $6 \%$ people thinks it is medium, $1 \%$ thinks it is less strong, $2 \%$ people thinks it is strongly related, while $8 \%$ people haven't answered It has been seen that $24 \%$ of people thinks drug use has no relationship with the disease while $10 \%$ thinks it is weakly related, $12 \%$ thinks it is less weak, $13 \%$ people thinks it is medium, $19 \%$ thinks it is less strong, $11 \%$ people thinks it is strongly related, while $11 \%$ people haven't answered. It has been seen that $46 \%$ of people thinks using public swimming pool has no relationship with the disease while $15 \%$ thinks it is weakly related, $9 \%$ thinks it is less weak, $15 \%$ people thinks it is medium, $4 \%$ thinks it is less strong, $2 \%$ people thinks it is strongly related, while $9 \%$ people haven't answered.

$19 \%$ of the participants selected proper diet as one of the factor which can reduce the risk of developing cervical cancer, $32 \%$ choose regular physical exercise can reduce the risk. While only $5 \%$ thinks proper sleep can reduce the risk and $83 \%$ of the participants thinks by avoiding multiple sexual partners the risk of developing cervical cancer can be reduced. Among the participants $43 \%$ of people had heard about douching and $55 \%$ haven't. While 2\% have left unanswered among the whole participants $30 \%$ people have heard about the vaccine against cervical cancer, $69 \%$ haven't heard about it and $1 \%$ people haven't answered. From the data, no one have taken vaccine against cervical cancer, $97 \%$ choose no. Just $1 \%$ people said they will take while $2 \%$ haven't answered anything.

Table 1 shows the percentage of people's view about the symptoms related with the disease. $43 \%$ of the participant thinks painful menstruation is associated with cervical cancer, $57 \%$ thinks symbols from genital area is one of the symptom. $39 \%$ people choose intensive periods, $36 \%$ people selected smelly vaginal discharge. While $50 \%$ people choose itching in the genital area as the symptom of cervical cancer. $55 \%$ choose bleeding after intercourse and $18 \%$ chooses high fever as the symptom which may be associated with cervical cancer. $76 \%$ people claim internet as their source of information about cervical cancer, $9 \%$ claims television as the source of information. $17 \%$ people are informed about it by the newspaper, $16 \%$ people knows about it from the doctors, $3 \%$ from school and 36\% from family and other sources like magazine, books etc.

Table I Shows the percentage of people's view about the symptoms related with the disease

\begin{tabular}{|c|c|c|c|c|c|c|c|}
\hline Risk factors & $\begin{array}{l}\text { No relationship } \\
\text { (o)in \% }\end{array}$ & $\begin{array}{l}\text { Weak } \\
\text { (1) in \% }\end{array}$ & $\begin{array}{l}\text { Less } \\
\text { Weak } \\
\text { (2) in \% }\end{array}$ & $\begin{array}{l}\text { Medium } \\
\text { (3) in \% }\end{array}$ & $\begin{array}{l}\text { Less } \\
\text { strong } \\
(4) \text { in \% }\end{array}$ & $\begin{array}{l}\text { Strongly } \\
\text { related } \\
(5) \text { in \% }\end{array}$ & $\begin{array}{l}\text { Not answer-ed }(x) \\
\text { in } \%\end{array}$ \\
\hline & & & & & & & \\
\hline Young Age & & 14 & 6 & 17 & 9 & 0 & 9 \\
\hline \multirow[t]{2}{*}{ Genetic factors } & & 9 & 14 & 21 & 21 & 25 & 3 \\
\hline & 7 & & & & & & \\
\hline HPV infection & 7 & 3 & 14 & 21 & 17 & 27 & 11 \\
\hline Multiple Sex partners & 4 & 8 & 6 & 12 & 26 & 40 & 4 \\
\hline HIV infection & 5 & 40 & 11 & 18 & 27 & 29 & 6 \\
\hline Alcohol Use & 29 & 9 & 13 & 23 & 11 & 3 & 12 \\
\hline Smoking & 31 & 8 & 20 & 13 & 16 & 7 & 5 \\
\hline Miscarriage \& abortions & 36 & 12 & 16 & 12 & 10 & 6 & 8 \\
\hline Large no of pregnancy & 37 & 11 & 10 & 19 & 7 & 11 & 5 \\
\hline \multirow{2}{*}{$\begin{array}{l}\text { Early Menarche } \\
\text { Use of condom }\end{array}$} & 41 & 16 & 12 & 11 & 9 & 0 & 11 \\
\hline & 28 & 8 & 17 & 16 & 8 & 12 & 11 \\
\hline \multicolumn{8}{|l|}{ Hormonal contraception } \\
\hline & 6 & 5 & 15 & 26 & 24 & 12 & 12 \\
\hline \multicolumn{8}{|l|}{ Breast feeding } \\
\hline & 60 & 14 & 9 & 6 & 1 & 2 & 8 \\
\hline Drug use & 24 & 10 & 12 & 13 & 19 & 11 & 11 \\
\hline Public swimming pool & 46 & 15 & 9 & 15 & 4 & 2 & 9 \\
\hline
\end{tabular}




\section{Descriptive analysis of what people know about cervical cancer}

From the study it is obtained maximum of the participants think cervical cancer is the cancer of cervix. Some mentioned only as female reproductive cancer. A few thinks it is basically occurred in men. During intercourse it is transmitted from men to women. Some defined as abornormal cell growth at the vagina. Many haven't even answered and some didn't know about it. Some defined it as an irritation of the cervix and some are them are even well knowledge about its vaccine. Even people defined cervical cancer as cancer at the uterus ending region at mouth of vagina while some others claim it the cancer of the uterus neck. Another variation in definition is it is a type of vaginal cancer which can affect conception of a baby; women may die out of it. It is also recognized as the cancer associated with the uterus tube by some.

\section{Discussion}

The study has been successfully developed to measure the level of knowledge on the subject of cervical cancer among young women. The questionnaire covers a significantly wider spectrum to find out the awareness of cervical cancer by categorizing certain risk factors associated with the disease which are to be marked in number range, as well as ways of primary prevention (HPV vaccination) and sources of information about cervical cancer. While maximum of the studies mainly aims at attitudes of women towards the Pap test. The present study revealed that $86 \%$ of the people had heard about cervical cancer which is quite a higher number. A Kolkata study among the college goers revealed a very level of knowledge about cervical cancer only $50 \%$ of the participants heard about it. ${ }^{12}$ A Yemeni study revealed that most respondents $(80.6 \%)$ had heard about cervical cancer with a quarter of the respondents $(26.4 \%)$ accessing this information from television. ${ }^{13}$

In Africa, a study in Kenya, to assess knowledge and practices about cervical cancer and Pap smear testing among cervical cancer and non cancer patients, found that $51 \%$ of the respondents were aware of cervical cancer which is lower than as obtained in the present study. From the present study it is revealed that $62 \%$ of the women believe cervical cancer can cause death but studies reveals that its early detection and screening can prevent death. A study conducted in Yemen where a great majority $(70 \%)$ of respondents was correctly informed that cervical cancer is preventable. ${ }^{13}$ In the present study, $49 \%$ participants think that cervical cancer is associated with an infection, $14 \%$ does not agree with an association of infection. In the present study, $27 \%$ people think HPV infection is strongly related risk factor of the disease. While in a study at Nigeria only $5.1 \%$ respondents who had heard of cervical cancer knows about HPV infection. None of the respondents in a study Conducted in Malaysia had heard of the HPV. ${ }^{14}$ Another study in US found $21.5 \%$ of the college women to have never heard of HPV. ${ }^{15}$ An England based study reveals only 13\% women identified the genetic factors as the risk factor of cervical cancer. The present study revealed $25 \%$ of the women identified genetic factor as strongly related risk factor of the disease. ${ }^{15}$

In the present study, $11 \%$ identified parity or large number of pregnancies as strongly related risk factor of cervical cancer and only $7 \%$ identified smoking as strongly related risk factor. A study on college students in Ghana had very low (1\%) awareness of the link between smoking and cervical cancer. ${ }^{16}$ In a Malaysian study, women aged 21-56years could not identify smoking and parity as risk factors. ${ }^{17}$ A Korean survey ${ }^{18}$ found $31.5 \%$ women know sexually transmitted infections (STIs) can cause cervix cancer. However, in the present study only $29 \%$ people think it is strongly related with cervical cancer. Studies in Asian countries also reported low knowledge levels of public on etiologic involvement of STIs and HPV in cervical cancer. ${ }^{19,20}$

A Kenya based study among the female primary school teachers reveled $53 \%$ of women identified, use of hormonal contraceptive as risk factors. ${ }^{20}$ In the present study only $12 \%$ identified hormonal contraception as strongly related risk factor and $24 \%$ marked it as less strong risk factor. In the present study, $40 \%$ of the women strongly identified multiple sexual partners as a risk factor of the disease. A Kolkata based study on collage goers revealed only (3\%) identified multiple sex partners as a risk factor. ${ }^{21}$ In the present study, $55 \%$ of the women chosen bleeding after intercourse and $36 \%$ chosen smelly vaginal discharge as the symptoms of cervical cancer. An England based study reveals $64 \%$ of the women selected vaginal bleeding during/after sex as one of the symptoms while $62 \%$ identified vaginal discharge that smells unpleasant. ${ }^{22}$

\section{Acknowledgements}

None.

\section{Conflict of interest}

The author declares no conflict of interest.

\section{References}

1. Arbyn M, Castellsague X, de Sanjose S, et al. Worldwide burden of cervical cancer in 2008. Ann Oncol. 2011;22(12):2675-2686.

2. Armstrong EP. Prophylaxis of cervical cancer and related cervical disease: a review of the cost-effectiveness of vaccination against oncogenic HPV types. J Manag Care Pharmpr. 2010;16(3):217-230.

3. American Cancer Society. Cancer Prevention and Early Detection Facts and Figures 2012. Atlanta, GA: American Cancer Society; 2012.

4. Moreno V, Bosch FX, Muñoz N, et al. Effect of oral contraceptives on risk of cervical cancer in women with human papillomavirus infection: The IARC multicentric case-control study. Lancet. 2002;359(9312):10851092.

5. Ferlay J, Shin HR, Bray F, et al. GLOBOCAN 2008 Cancer Incidence and Mortality Worldwide: IARC CancerBase No.10. Lyon, France: International Agency for Research on Cancer; 2010.

6. Shanta V. Perspectives in cervical cancer prevention in India. The international network for cancer treatment and research; 2003.

7. Marrazzo JM. Genital human papillomavirus infection in women who have sex with women: A concern for patients and providers. AIDS Patient Care STDS. 2000;14(8):447-451.

8. Nnodu O, Erinosho L, Jamda M, et al. Knowledge and attitudes towards cervical cancer and human papillomavirus: a Nigerian pilot study. Afr $J$ Reprod Health. 2010;14(1):95-108.

9. Louie KS, Castellsague X, de Sanjose S, et al. Smoking and passive smoking in cervical cancer risk: Pooled analysis of couples from the IARC multicentric case-control studies. Cancer Epidemiol Biomarkers Prev. 2011;20(7):1379-1390. 
10. Nganwai $\mathrm{P}$, Truadpon $\mathrm{P}$, Inpa $\mathrm{C}$, et al. Knowledge, attitudes and practices vis-a-vis cervical cancer among registered nurses at the faculty of medicine, Khon Kaen University, Thailand. Asian Pac J Cancer Prev. 2008;9(1):15-18.

11. Kamzol W, Jaglarz K, Tomaszewski KA, et al. Assessment of knowledge about cervical cancer and its prevention among female students aged 17-26years. Eur J Obstet Gynecol Reprod Biol. 2013;166(2):196-203.

12. Saha A, Chaudhury AN, Bhowmik P, et al. Awareness of cervical cancer among female students of premier colleges in Kolkata, India. Asian Pac J Cancer Prev. 2010;11(4):1085-1090.

13. M. Abdul-Aziz. Knowledge, attitude and practice towards cervica cancer among reproductive health clients at the University of Science \& Technology Hospital-Sana'a in Yemen. Yemeni Journal for Medical Sciences. 2012;6:21-27.

14. Wong LP1, Wong YL, Low WY, et al. "Knowledge and awareness of cervical cancer and screening among Malaysian women who have never had a Pap smear: A qualitative study Singapore. Med J. 2009;50(1):49-53

15. Jo Waller. Report on Awareness Levels of Cervical Cancer amongst Women in England The Eve Appeal June 2010: What Women Know.

16. Abotchie PN, Shokar NK. Cervical cancer screening among college students in Ghana: Knowledge and health beliefs. Int J Gynecol Cancer. 2009;19(3):412-416.
17. Oh JK, Lim MK, Yun EH, et al. Awareness of and attitude towards human papillomavirus infection and vaccination for cervical cancer prevention among adult males and females in Korea: A nationwide interview survey. Vaccine. 2010;28(7):1854-1860.

18. Dinh TA1, Rosenthal SL, Doan ED, et al. Attitudes of mothers in Da Nang, Vietnam toward a human papillomavirus vaccine. J Adolesc Health. 2007;40(6):559-563

19. Lee M. Knowledge, Barriers, and motivators related to cervical cancer screening among Korean-American women. Cancer Nurs. 2000;23(3):168-175.

20. Shah V, Vyas S, Singh A, et al. Awareness and knowledge of cervical cancer and its prevention among the nursing staff of a tertiary health institute in Ahmadabad. Ecancermedicalscience. 2012;6:270

21. Ombech EA, Muigai A, Wanzala Peter WT. Awareness of cervical cancer risk factors and practice of pap smear testing among female primary school teachers in Kasarani division, Nairobi Kenya. African Journal of Health Sciences. 2012;21:121-132. 